\title{
Synthesis and selected immunological properties of 10-substituted 1,8-diazaphenothiazines
}

\author{
Beata Morak-Młodawska $\cdot$ Krystian Pluta $\cdot$ Michał Zimecki • \\ Małgorzata Jeleń · Jolanta Artym • Maja Kocięba
}

Received: 30 December 2013/Accepted: 2 August 2014/Published online: 19 August 2014

(C) The Author(s) 2014. This article is published with open access at Springerlink.com

\begin{abstract}
A new type of tricyclic azaphenothiazines1,8-diazaphenothiazines-was obtained in the reaction of 2,3- and 3,4-disubstituted pyridines. The reaction ran as the Smiles rearrangement. The 1,8-diazaphenothiazine system was determined using NOE experiment and 2D NMR spectra (COSY, HSQC, HMBC). 10H-1,8-diazaphenothiazine was transformed into 10-derivatives with alkyl, aminoalkyl, amidoalkyl, sulfonamidoalkyl, and nitrogen half-mustard groups. The compounds were tested for their effects on phytohemagglutinin A-induced proliferative response of human peripheral blood mononuclear cells (PBMC) and lipopolysaccharide-induced tumor necrosis factor alpha production by human whole blood cultures. The compounds exhibited differential, dose-dependent inhibitory activities in these tests. All the compounds were low toxic against PBMC. The compounds showing the highest antiproliferative activity strongly inhibited the growth of leukemia L-1210 and colon cancer SW-948 cell lines, similarly as cisplatin, a reference drug.
\end{abstract}

Keywords Phenothiazines - Diazaphenothiazines · Antiproliferative activity - Anticancer activity . Thiazine ring formation

B. Morak-Młodawska $\cdot$ K. Pluta $(\bowtie) \cdot$ M. Jeleń Department of Organic Chemistry, The Medical University of Silesia, Jagiellońska 4, 41-200 Sosnowiec, Poland e-mail: pluta@sum.edu.pl

M. Zimecki · J. Artym · M. Kocięba

Department of Experimental Therapy, Institute of Immunology and Experimental Therapy, Polish Academy of Sciences, R. Weigla 12, 53-114 Wrocław, Poland

\section{Introduction}

Tricyclic phenothiazines attract considerable attention because of their significant biological activities and interesting chemical features. Classical phenothiazines with aminoalkyl substituents at the nitrogen atom are the source of valuable drugs exhibiting neuroleptic, antihistaminic, antitussive, and antiemetic activities (Gupta and Kumar, 1988). The structure modifications of these compounds were carried out by introduction of new substituents, mainly at the thiazine nitrogen atom, and substitution of one or two benzene rings with homoaromatic and heteroaromatic rings. The modifications with azine rings lead to formation of azaphenothiazines. New phenothiazines can contain not only the tricyclic ring system but also tetra and pentacyclic ones with up to four additional nitrogen atoms in the aromatic rings (Silberg et al., 2006; Pluta et al., 2009, 2011). Such modifications can change potency and type of activities of the basic structures. Recent reports describe very promising anticancer, antibacterial, and antiinflammatory activities, reversal of multidrug resistance and a potential benefit in treatment of Alzheimer's, Creutzfeldt-Jakob's and AIDS-associated diseases for the modified phenothiazines (Motohashi et al., 2000, 2006; Dasgupta et al., 2008; Sadandam et al., 2009; Aaron et al., 2009; Tandon et al., 2009; Pluta et al., 2011).

Our strategy for modification of the phenothiazine structure is based on the introduction of two pyridine rings instead of the benzene ones to form dipyrido[1,4]thiazines. Among ten theoretically possible dipyridothiazines types only four have been known before introduction of our research strategy, i.e., 1,6- (Maki, 1957; Takahashi and Maki, 1958a, b; Rodig et al., 1966), 1,9- (Rath, 1957), 2,7(Kopp et al., 1963; Kopp and Strell, 1962), and 3,6-diazaphenothiazines (Okafor, 1967). Three nomenclature 
Scheme 1 Synthesis if $10 \mathrm{H}$ diazaphenothiazine $\mathbf{3}$ from disubstituted pyridines $\mathbf{2}$ and $\mathbf{3}$ and dipyridyl sulfide $\mathbf{5}$
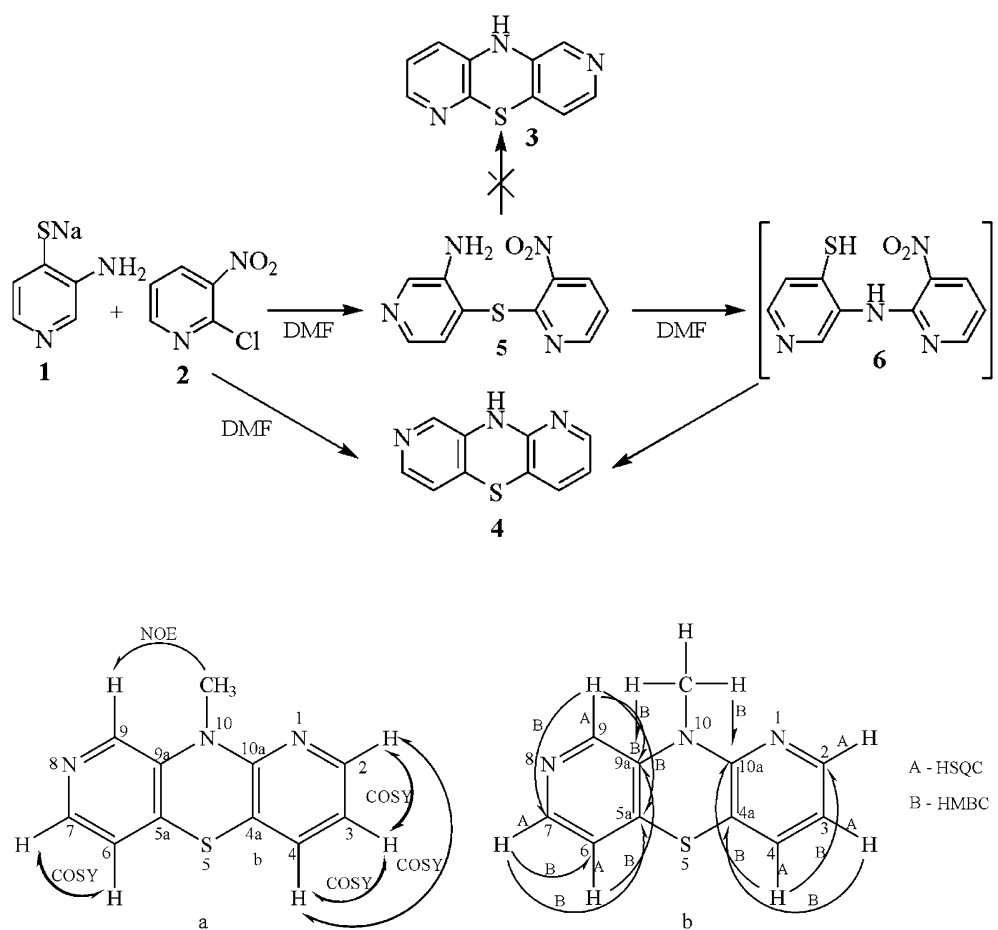

Scheme 2 The NMR

experiments for compound $\mathbf{7}$ : $a \mathrm{NOE}$ and COSY, $b$ HSQC and HMBC systems of phenothiazines with different atom numbering, valid in the sixties and seventies, were confusing. 2,7-Diazaphenothiazines described by Kopp and co-workers were in fact 3,7-diazaphenothiazines (Pluta et al., 2009). Correct 2,7-diazaphenothiazines were obtained by us and their ring system was confirmed by X-ray analysis (Morak et al., 2002; Morak and Pluta, 2007). The parent compound, 10H-2,7diazaphenothiazine, was found to be a universal, low-toxic immunosuppressant, inhibiting both humoral and cellular immune responses, and antioxidant property (Zimecki et al., 2009; Morak-Młodawska et al., 2010; Pluta et al., 2010).

In continuation of our studies, we have worked out an efficient synthesis of a new type of dipyridothiazines, $10 \mathrm{H}$ 1,8-diazaphenothiazine and its 10 -substituted derivatives, possessing alkyl, arylalkyl, aryl, heteroaryl and aminoalkyl, amidoalkyl, sulfonamidoalkyl, and nitrogen halfmustard type substituents. In this work, we discuss their synthesis and structures and test their activities in selected biological assays.

\section{Results and discussion}

\section{Chemistry}

It is well known that the synthesis of phenothiazines and azaphenothiazines may proceed via cyclization of diphenyl sulfides, phenyl azinyl sulfides, or diazinyl sulfides directly as the Ullmann cyclization or with the Smiles rearrangement of the $\mathrm{S} \rightarrow \mathrm{N}$ type depending on the reaction conditions. In the last case, the phenyl or azinyl part migrates from the sulfur atom to the nitrogen atom forming amine and subsequently phenothiazine or azaphenothiazine. The rearrangement proceeds most often under basic but also under acidic and neutral conditions. Sometimes it is impossible to state if a reaction runs with or without the rearrangement because the Ullmann and Smiles products are the same or very similar (Pluta et al., 2009).

We started the synthesis with a reaction of sodium 3-aminopyridinothiolate (1) with 2-chloro-3-nitropyridine (2) in refluxing DMF. After isolation and purification of the products we found dipyridothiazine (2,6-diazaphenothiazine 3 or 1,8-diazaphenothiazine 4) as the major product in $88 \%$ yield and $3^{\prime}$-amino-3-nitro-2,4'-dipyridyl sulfide (5) in $9 \%$ yield as the minor product (Scheme 1). The mass spectrum confirmed the diazaphenothiazine structure $(M=201)$ but the ${ }^{1} \mathrm{H}$ NMR spectrum does not point at the structure 3 or $\mathbf{4}$ as both compounds are built of the 2,3- and 3,4-pyridinediyl units giving a singlet $(7.90 \mathrm{ppm})$, two doublets $(7.18,8.07 \mathrm{ppm})$, and three doublets of doublet $(6.90,7.26,8.09 \mathrm{ppm})$ of the proton signals. To unquestionably determine the diazaphenothiazine structure, we transformed the product into the $\mathrm{N}$-methyl derivative (vide infra). The differentiation between 1,8- and 2,6-diazaphenothiazine system was based on the NOE experiment of this derivative. Irradiation of the methyl protons at $3.44 \mathrm{ppm}$ (Scheme 2) gave an enhancement only of one proton, the singlet signal at $7.90 \mathrm{ppm}$ by $7.06 \%$ what pointed at the 1,8-diazaphenothiazine system and the derivative 7 (Scheme 3). 
Scheme 3 Synthesis of 10-dialkylaminoalkyl-1,8diazaphenothiazines 7-19
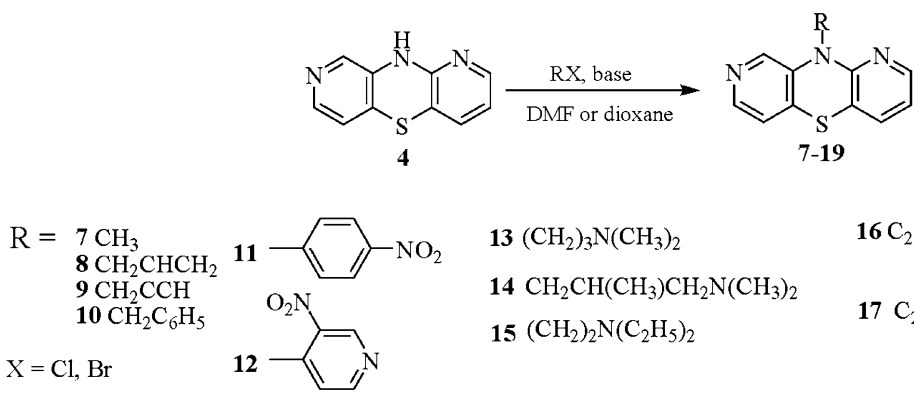

$13\left(\mathrm{CH}_{2}\right)_{3} \mathrm{~N}\left(\mathrm{CH}_{3}\right)_{2}$

$14 \mathrm{CH}_{2} \mathrm{CH}\left(\mathrm{CH}_{3}\right) \mathrm{CH}_{2} \mathrm{~N}\left(\mathrm{CH}_{3}\right)_{2}$ $15\left(\mathrm{CH}_{2}\right)_{2} \mathrm{~N}\left(\mathrm{C}_{2} \mathrm{H}_{5}\right)_{2}$

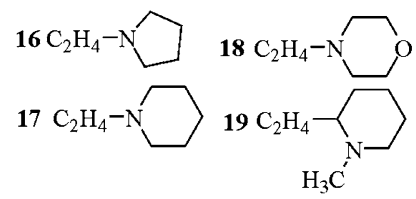

Scheme 4 Synthesis of 10-phthalimidopropyl-1,8-diazaphenothiazine 20 and transformations to the acetamidopropyl, methanesulfonamidopropyl, and chloroethylureidopropyl derivatives 22-24

The full ${ }^{1} \mathrm{H}$ NMR assignment of the proton signals came from the homonuclear ${ }^{1} \mathrm{H}-{ }^{1} \mathrm{H}$ correlation (COSY). Three most deshielded proton signals at 7.90, 8.07, and 8.09 ppm were considered as the $\alpha$-pyridinyl proton signals. The doublet of doublet signal at $6.90 \mathrm{ppm}$, considered as the $\beta$-pyridinyl proton, was intercorrelated (ortho-coupling) with the signals at $8.09 \mathrm{ppm}$ and at $7.26 \mathrm{ppm}$ ( $\gamma$-pyridinyl proton) with the coupling constants of 4.9 and $7.2 \mathrm{~Hz}$, respectively. The signal at $7.26 \mathrm{ppm}$ was weak intercorrelated (para-coupling) with the signal at $8.09 \mathrm{ppm}$ with the coupling constant of $1.8 \mathrm{~Hz}$. The protons were assigned as $\mathrm{H}_{3}, \mathrm{H}_{4}$, and $\mathrm{H}_{2}$, respectively. The $\alpha$-pyridinyl proton signal at $8.07 \mathrm{ppm}$ was correlated with the signal at $7.18 \mathrm{ppm}$ ( $\beta$-pyridinyl proton) with the coupling constant of $5.4 \mathrm{~Hz}$. These protons were assigned as $\mathrm{H}_{7}$ and $\mathrm{H}_{6}$. The proton signal assignment was presented in Scheme 2.

The new diazaphenothiazine system was also determined by the ${ }^{13} \mathrm{C}$ NMR spectrum. The spectrum revealed eleven carbon signals: one primary, six tertiary, and four quaternary. The methyl group was observed at $32.8 \mathrm{ppm}$. The full assignment of carbon signals came from 2D NMR: HSQC (the tertiary carbon atoms connected with the hydrogen atoms) and HMBC (the tertiary and quaternary carbon atoms correlated with the hydrogen atoms via two and mainly three bonds). The proton-carbon correlation was presented in Scheme 2.

The product structure as $10 \mathrm{H}$-1,8-diazaphenothiazine $\mathbf{4}$ is the evidence for the Smiles rearrangement of the S-N type of resulted dipyridinyl sulfide $\mathbf{5}$. Heating sulfide $\mathbf{5}$ in refluxing DMF gave 10H-1,8-diazaphenothiazine (4) in $88 \%$ yield. The reaction run through the formation of dipyridinyl amine $\mathbf{6}$ which (not isolated) very easily cyclized to diazaphenothiazine 4 (Scheme 1). The 1,8-diazaphenothiazine ring system was confirmed by X-ray analysis of the nitropyridyl derivative 12 (obtained by independent way from appropriate sulfide containing three nitropyridyl moieties via the double Smiles rearrangement), published separately (Morak-Młodawska et al., 2012).

The parent $10 H-1,8$-diazaphenothiazine 4 was transformed into 10-derivative in one or three steps. The alkylation with alkyl (methyl, allyl, propargyl, benzyl), aryl (pnitrophenyl) and heteroaryl (3-nitro-4-pyridinyl) halides and aminoalkyl (3-dimethylaminopropyl, 3-dimethylamino2-methylpropyl, 2-diethylaminoethyl, 1-pyrrolidinoethyl, 1-piperidinoethyl, 1-methyl-2-piperidinoethyl, 1-morpholinoethyl) in DMF in the presence of sodium hydride or potassium tert-butoxide and in dioxane in the presence of sodium hydroxide gave derivatives $\mathbf{7 - 1 9}$ in good yields Scheme 3).

The substrate $\mathbf{4}$ was also transformed into compounds possessing aminopropyl derivative substituents. Reaction of compound $\mathbf{4}$ with the phthalimidopropyl bromide in toluene in the presence of sodium hydride gave the phthalimidopropyl derivative 20. The hydrolysis of this compound with hydrazine in ethanol led to aminopropyl derivative $\mathbf{2 1}$ which quickly (because of their instability) underwent reactions 
Table 1 Activities of 10-substituted 1,8-diazaphenothiazines in selected immunological assays

\begin{tabular}{|c|c|c|c|c|c|c|}
\hline \multirow[t]{2}{*}{ No. } & \multicolumn{2}{|c|}{$\begin{array}{l}\text { Cytotoxicity } \\
\text { against PBMC }\end{array}$} & \multicolumn{3}{|c|}{$\begin{array}{l}\text { Inhibition of PHA-induced } \\
\text { PBMC proliferation }\end{array}$} & \multirow{2}{*}{$\begin{array}{l}\text { TNF- } \alpha \\
\text { inhibition } \\
5 \mu \mathrm{g} / \mathrm{ml}\end{array}$} \\
\hline & $10 \mu \mathrm{g} / \mathrm{ml}$ & $50 \mu \mathrm{g} / \mathrm{ml}$ & $1 \mu \mathrm{g} / \mathrm{ml}$ & $10 \mu \mathrm{g} / \mathrm{ml}$ & $50 \mu \mathrm{g} / \mathrm{ml}$ & \\
\hline 4 & 6.7 & 21.4 & 5.0 & 74.4 & 78.6 & 50.4 \\
\hline 7 & 0.8 & 1.7 & 9.6 & 22.9 & 45.6 & 76.4 \\
\hline 8 & -0.3 & -6.0 & 19.0 & 26.0 & 55.6 & 89.3 \\
\hline 9 & -1.1 & 8.8 & 9.3 & 24.4 & 41.2 & 87.4 \\
\hline 10 & 2.0 & 2.6 & 13.6 & 26.8 & 45.5 & 85.9 \\
\hline 12 & 6.6 & 8.1 & 4.1 & 5.2 & 26.2 & 54.8 \\
\hline 13 & -3.6 & 15.0 & 5.7 & 20.9 & 81.1 & 86.7 \\
\hline 14 & -0.7 & 11.9 & 1.4 & 19.2 & 59.4 & 89.1 \\
\hline 15 & 1.3 & 12.1 & -6.8 & -5.4 & 59.6 & 75.0 \\
\hline 16 & 0.9 & 10.0 & -0.9 & -2.9 & 47.0 & 85.6 \\
\hline 17 & 1.5 & 7.3 & -0.9 & -0.5 & 18.0 & 47.6 \\
\hline 18 & -1.4 & 18.7 & -3.4 & 5.1 & 67.4 & 73.1 \\
\hline 19 & -4.5 & 4.8 & -0.9 & 7.0 & 18.2 & 46.1 \\
\hline 20 & -2.0 & -0.1 & 3.6 & 12.5 & 42.2 & 76.0 \\
\hline 22 & -5.0 & 6.7 & 8.9 & 16.2 & 62.5 & 5.8 \\
\hline 23 & -0.9 & 12.5 & 9.4 & 19.3 & 50.2 & 48.6 \\
\hline 24 & -1.6 & 4.5 & 8.4 & 12.4 & 46.8 & 7.3 \\
\hline
\end{tabular}

The table shows the degree of cytotoxicity against PBMC, effects on PHA-induced proliferative response of human PBMC and LPSinduced TNF- $\alpha$ production by these cells. The results are given in percentage inhibition as compared with appropriate DMSO controls. Positive values denote inhibition, negative stimulation

with acetic anhydride, methanesulfonyl chloride, and 2-chloroethyl isocyanate to give acetamidopropyl, methanesulfonamidopropyl, and chloroethylureidopropyl derivatives 22-24 in 63-80\% yield (Scheme 4).

\section{Biological activities}

10-substituted 1,8-diazaphenothiazines 4, 7-10, 12-20, and 22-24, possessing various substituents (hydrogen atom, alkyl groups with single, double, and triple bonds, arylalkyl, heteroaryl, alkylaminoalkyl, amidoalkyl, sulfonamidoalkyl and alkyl with a half-mustard-type group) were tested for their biological activities. The tests included the proliferative response of human peripheral blood mononuclear cells (PBMC) induced by phytohemagglutinin A (PHA), the cytotoxic effect on human PBMC and lipopolysaccharide (LPS)-induced production of tumor necrosis factor alpha (TNF- $\alpha$ ). The combined results of the tests are presented in Table 1. The most promising compounds, selected on the basis of their strong antiproliferative effects, were tested for growth inhibition of leukemia L-1210 cells and colon carcinoma SW-948 cells in vitro.
The proliferation test was performed at the concentrations of 1,10 , and $50 \mu \mathrm{g} / \mathrm{ml}$. A strong activity (inhibition over $70 \%$ ) was exhibited by compound: 4 at $10 \mu \mathrm{g} / \mathrm{ml}$ and compound $\mathbf{1 3}$ at $50 \mu \mathrm{g} / \mathrm{ml}$ in comparison with the control cultures (culture medium containing appropriate dilution of DMSO). These compounds possess the hydrogen atom and dimethylaminopropyl groups at position 10. A moderate activity (inhibition about $60 \%$ at $50 \mu \mathrm{g} / \mathrm{ml}$ ) was exhibited by compounds: 14, 15, 18, and 22 (the dimethylamino-2methylpropyl, diethylaminoethyl, 1-methyl-2-piperidinoethyl, and acetamidopropyl groups). Other compounds were weakly active or inactive.

In order to check whether the inhibitory effects of the compounds were not caused by cytotoxicity, the compounds were tested for their effects on viability of PBMC. All the compounds exhibited very weak cytotoxic properties with the inhibition of cell viability not exceeding $22 \%$ even at $50 \mu \mathrm{g} / \mathrm{ml}$. Because lack of toxicity at $1 \mu \mathrm{g} / \mathrm{ml}$ that concentration of the compounds was deleted in Table 1.

The compounds were also tested for their inhibitory effects on LPS-induced TNF- $\alpha$ production at the concentrations of 5 and $25 \mu \mathrm{g} / \mathrm{ml}$. No further inhibition of TNF- $\alpha$ production was registered for $25 \mu \mathrm{g} / \mathrm{ml}$ and, therefore, not shown in Table 1. Compounds $\mathbf{8 - 1 0}, \mathbf{1 3}, \mathbf{1 4}$, and $\mathbf{1 6}$ showed inhibitions of over $85 \%$ at $5 \mu \mathrm{g} / \mathrm{ml}$.

The most promising compounds $4,8,13$, and 22 (being strongly antiproliferative and low cytotoxic) were selected for evaluation of anticancer activities against the cancer cell lines at the concentrations of $0.1-50 \mu \mathrm{g} / \mathrm{ml}$ using cisplatin as the reference drug (Fig. 1). The most active was compound 4, exhibiting similar anticancer activity to cisplatin against colon carcinoma SV-948 cells at the concentration of $5 \mu \mathrm{g} /$ $\mathrm{ml}$ and against leukemia L-1210 cells at $10 \mu \mathrm{g} / \mathrm{ml}$ (Table 2). Compounds 13 and 22 showed strong inhibition at $10 \mu \mathrm{g} /$ $\mathrm{ml}$. It is worth noting that cisplatin showed high toxicity killing of $50 \%$ of granulocyte/macrophage progenitor cells already at $0.9 \mu \mathrm{g} / \mathrm{ml}$ after $1 \mathrm{~h}$ of culture (Umbach et al., 1984). The drug is also nephrotoxic (Yao et al., 2007). The ability of the compounds (in particular 4 and 13) to strongly inhibit TNF- $\alpha$ may be of additional advantage in anti-tumor therapy. Although TNF- $\alpha$ may have a dual role in tumor progression (Wajant, 2009) some anti-tumor strategies aim at inhibition of its activity (Guadagni et al., 2007).

It is interesting that the most active was compound $\mathbf{4}$, possessing the hydrogen atom instead of the pharmacophoric aminoalkyl substituents at the thiazine nitrogen atom. It seems that compound $\mathbf{4}$ displays a different mechanism of action than that found for substituted phenothiazines and azaphenothiazines with the acylaminoalkyl and chloroethylureidoalkyl groups (Motohashi et al., 2000, 2006; Pluta et al., 2011). 


\section{SV 948}

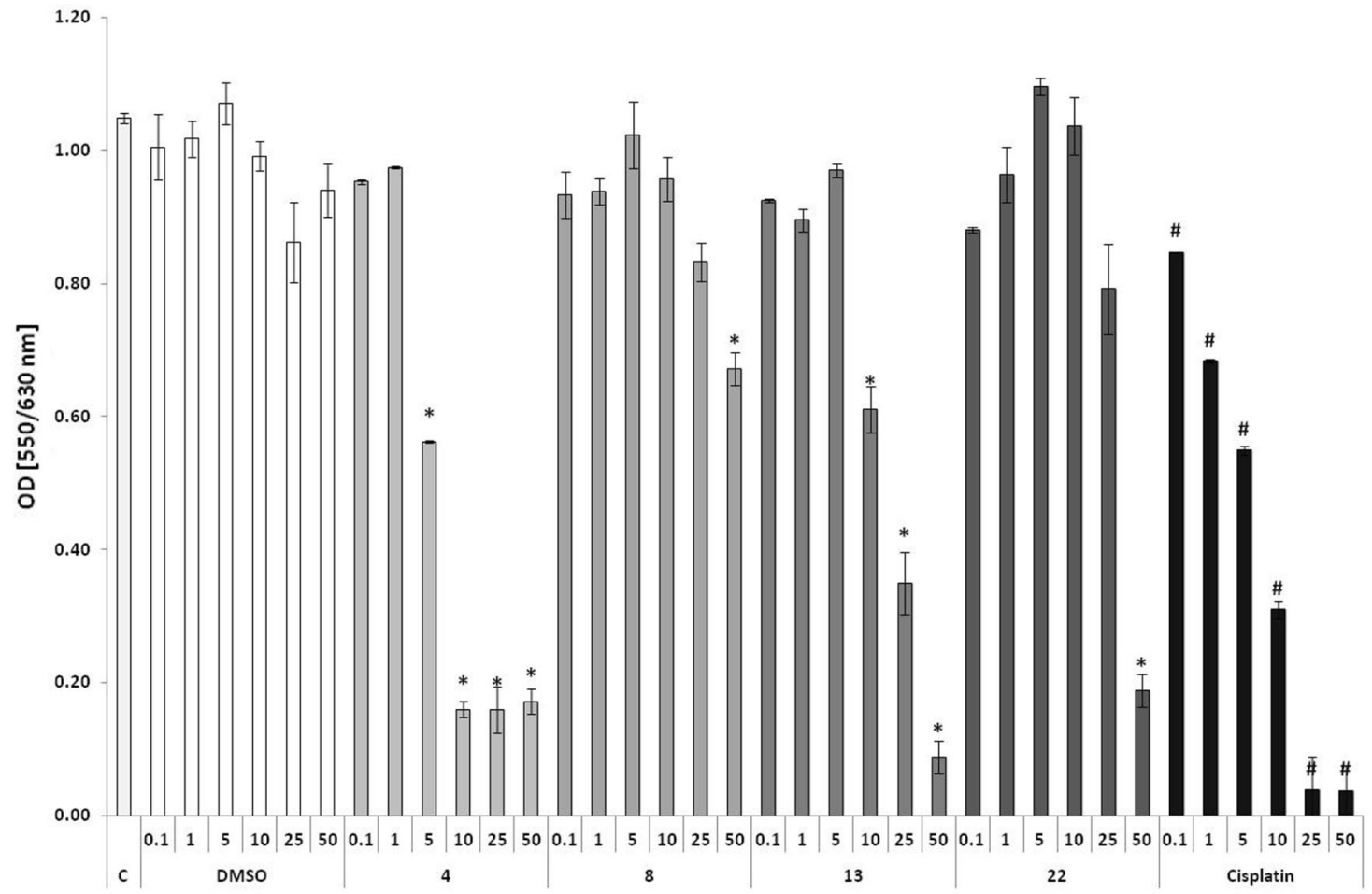

$\mathbf{L 1 2 1 0}$

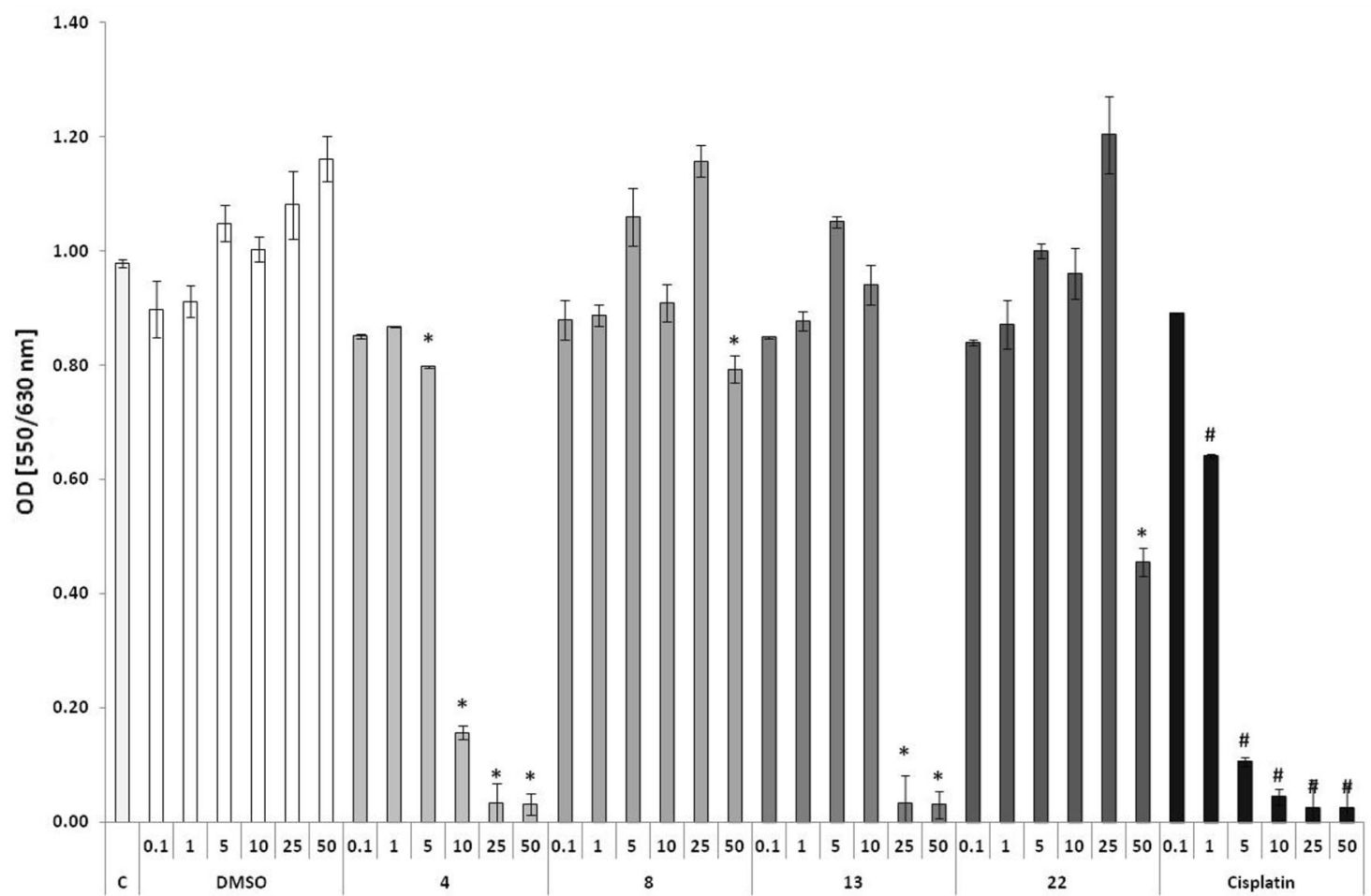

Fig. 1 The anticancer activities of selected compounds at concentrations of $0.1-50 \mu \mathrm{g} / \mathrm{ml}$. L-1210 and SW-948 cell lines were used in the study. The results are presented as the mean optical density $\pm \mathrm{SE}$ (*versus DMSO; ${ }^{*}$ versus Control, $p<0.001$ ) 
Table 2 Anticancer activity $\left(\mathrm{IC}_{50}\right)$ of selected compounds $\mathbf{4}$ and $\mathbf{1 3}$ and cisplatin as a reference drug against cancer lines SW-948 and L-1210

\begin{tabular}{lcc}
\hline Compound & $\mathrm{IC}_{50}(\mu \mathrm{g} / \mathrm{ml})$ & \\
\cline { 2 - 3 } & $\mathrm{SW}-948$ & $\mathrm{~L}-1210$ \\
\hline $\mathbf{4}$ & 5.47 & 7.41 \\
$\mathbf{1 3}$ & 14.95 & 6.03 \\
Cisplatin & 5.52 & 2.13 \\
\hline
\end{tabular}

\section{Conclusion}

We report here a few step synthesis and biological activity of novel tricyclic $10 \mathrm{H}$ - and 10-substituted 1,8-diazaphenothiazines. The synthesis was run through the Smiles rearrangement of $\mathrm{S}-\mathrm{N}$ type. The structure diazaphenothiazine system was elucidated using the NOE experiment and $2 \mathrm{D}\left({ }^{1} \mathrm{H}-{ }^{1} \mathrm{H}\right.$ and $\left.{ }^{1} \mathrm{H}-{ }^{13} \mathrm{C}\right)$ spectra. Some 1,8-diazaphenothiazines exhibited antiproliferative, anticancer, TNF- $\alpha$ inhibitory activities with low cytotoxicity. The new diazaphenothiazine system was found to be pharmacophoric as $10 H$-1,8-diazaphenothiazine was the most active, with anticancer activities comparable to that of cisplatin. This compound seems to be a useful starting point for further study to found more potent anticancer agents by introduction of new substituents at the thiazine nitrogen atom.

\section{Experimental}

\section{Chemistry}

Melting points were determined in open capillary tubes on a Boetius melting point apparatus and are uncorrected. The ${ }^{1} \mathrm{H}$ NMR, COSY, NOE HSQC, HMBC spectra were recorded on a Bruker Fourier 300 and Bruker DRX spectrometers at 300 and $600 \mathrm{MHz}$ in deuteriochloroform with tetramethylsilane as the internal standard. The ${ }^{13} \mathrm{C} N \mathrm{NM}$ spectrum was recorded at $75 \mathrm{MHz}$. Electron Impact mass spectra (EI MS) and Fast Atom Bombardment mass spectra (FAB MS, in glycerol) were run on a Finnigan MAT 95 spectrometer at $70 \mathrm{eV}$. The thin layer chromatography were performed on silica gel $60 \mathrm{~F}_{254}$ (Merck 1.05735) with $\mathrm{CHCl}_{3}$-EtOH (5:1 and 10:1 v/v) and on aluminum oxide 60 $\mathrm{F}_{254}$ neutral (type E) (Merck 1.05581) with $\mathrm{CHCl}_{3}-\mathrm{EtOH}$ $(10: 1 \mathrm{v} / \mathrm{v})$ as eluents.

\section{Synthesis of 10H-1,8-diazaphenothiazine (4)}

From sodium 3-amino-4-pyridinethiolate (1) and 2-chloro3-nitropyridine (2) To a solution of $148 \mathrm{mg}$ (1 mmol) sodium 3-amino-4-pyridinethiolate (1) in $10 \mathrm{ml}$ dry DMF was added $158 \mathrm{mg}$ (1 mmol) 2-chloro-3-nitropyridine (2). The mixture was stirred at $\mathrm{rt} 3 \mathrm{~h}$ and next was refluxed $3 \mathrm{~h}$. After cooling, the reaction mixture was evaporated in vacuo. The dry residue was dissolved in $\mathrm{CHCl}_{3}$ and purified by column chromatography (aluminum oxide, $\mathrm{CHCl}_{3}$ ) to give (a) $10 H$-1,8-diazaphenothiazine (4) $(0.125 \mathrm{~g}, 62 \%) \mathrm{mp}$
$135-136{ }^{\circ} \mathrm{C}$.

${ }^{1} \mathrm{H}$ NMR $\left(\mathrm{CDCl}_{3}\right) \delta 6.73(\mathrm{dd}, J=7.5 \mathrm{~Hz}, J=5.1 \mathrm{~Hz}$, $\left.1 \mathrm{H}, \mathrm{H}_{3}\right), 6.84\left(\mathrm{~d}, J=5.0 \mathrm{~Hz}, 1 \mathrm{H}, \mathrm{H}_{6}\right), 7.11(\mathrm{dd}$, $\left.J=7.5 \mathrm{~Hz}, J=1.5 \mathrm{~Hz}, 1 \mathrm{H}, \mathrm{H}_{4}\right), 7.69$ (board s, $\left.1 \mathrm{H}, \mathrm{N}-\mathrm{H}\right)$, $7.84\left(\mathrm{dd}, J=5.1 \mathrm{~Hz}, J=1.5,1 \mathrm{H}, \mathrm{H}_{2}\right), 7.89\left(\mathrm{~s}, 1 \mathrm{H}, \mathrm{H}_{9}\right)$, $7.95\left(\mathrm{~d}, J=5,0 \mathrm{~Hz}, 1 \mathrm{H}, \mathrm{H}_{7}\right) .{ }^{13} \mathrm{C} \mathrm{NMR}\left(\mathrm{CDCl}_{3}\right) \delta 112.2$ $\left(\mathrm{C}_{4 \mathrm{a}}\right), 118.9\left(\mathrm{C}_{3}\right), 120.5\left(\mathrm{C}_{6}\right), 128.9\left(\mathrm{C}_{5 \mathrm{a}}\right), 134.3\left(\mathrm{C}_{4}\right), 134.4$ $\left(\mathrm{C}_{9}\right), 136.9\left(\mathrm{C}_{9 \mathrm{a}}\right), 143.1\left(\mathrm{C}_{7}\right), 145.9\left(\mathrm{C}_{2}\right), 152.1\left(\mathrm{C}_{10 \mathrm{a}}\right)$. EI MS m/z: 201 (M, 100), 174 (M-HCN, 30). Anal. Calcd for: $\mathrm{C}_{10} \mathrm{H}_{7} \mathrm{~N}_{3} \mathrm{~S}, \mathrm{C} 59.68, \mathrm{H} 3.51, \mathrm{~N} 20.88$; S 15.93. Found: C 59.49, H 3.53, N 20.80; S 15.79.

(b) 3-amino-3'-nitro-2, $4^{\prime}$-dipyridinyl sulfide (5) (0.025 g, $9 \%$ ) mp $147-148{ }^{\circ} \mathrm{C}$.

In cyclization of 3-amino-3'-nitro-2,4'-dipyridinyl sulfide (5) The brown solution of $124 \mathrm{mg}(0.5 \mathrm{mmol}) 3$-amino$3^{\prime}$-nitro-2,4'-dipyridinyl sulfide 5 in $5 \mathrm{ml}$ dry DMF was refluxed for $4 \mathrm{~h}$. After cooling, the reaction mixture was evaporated in vacuo. The dry residue was dissolved in $\mathrm{CHCl}_{3}$ and purified by column chromatography (aluminum oxide, $\mathrm{CHCl}_{3}$ ) to give $10 \mathrm{H}$-1,8-diazaphenothiazine (4) $(0.088 \mathrm{~g}, 88 \%)$

Synthesis of 10-substituted 1,8-diazaphenothiazines 7, 8, and 10-12

To a solution of $10 \mathrm{H}$-1,8-diazaphenothiazine (4) $(0.100 \mathrm{~g}$, $0.5 \mathrm{mmol})$ in dry $\operatorname{DMF}(5 \mathrm{ml}) \mathrm{NaH}(0.024 \mathrm{~g}, 1 \mathrm{mmol}$, $60 \% \mathrm{NaH}$ in mineral oil was washed out with hexane) was added. The reaction mixture was stirred at room temperature for $1 \mathrm{~h}$ and then alkyl, aryl, and heteroaryl halides (methyl iodide, allyl bromide, benzyl chloride, 1-fluoro-4nitrobenzene, 4-chloro-3-pyridine, $1.5 \mathrm{mmol}$ ) were added and the stirring was continued for $24 \mathrm{~h}$. The mixture was poured into water $(15 \mathrm{ml})$, extracted with $\mathrm{CHCl}_{3}$ $(3 \times 10 \mathrm{ml})$, and dried using $\mathrm{Na}_{2} \mathrm{SO}_{4}$. The obtained product was purified by column chromatography (aluminum oxide, $\mathrm{CHCl}_{3}$ ) to give

10-Methyl-1,8-diazaphenothiazine (7) (0.085 g, $79 \%$ ); mp 82-83 ${ }^{\circ} \mathrm{C} \quad{ }^{1} \mathrm{H}$ NMR $\left(\mathrm{CDCl}_{3}\right) \delta 3.44\left(\mathrm{~s}, 3 \mathrm{H}, \mathrm{CH}_{3}\right), 6.90$ $\left(\mathrm{dd}, J=7.2 \mathrm{~Hz}, J=4.9 \mathrm{~Hz}, 1 \mathrm{H}, \mathrm{H}_{3}\right), 7.18(\mathrm{~d}, J=5.4 \mathrm{~Hz}$, $\left.1 \mathrm{H}, \mathrm{H}_{6}\right), 7.26\left(\mathrm{dd}, J=7.8 \mathrm{~Hz}, J=1.8 \mathrm{~Hz}, 1 \mathrm{H}, \mathrm{H}_{4}\right), 7.90$ (s, $\left.1 \mathrm{H}, \mathrm{H}_{9}\right), 8.07$ (d, $\left.J=5.4 \mathrm{~Hz}, 1 \mathrm{H}, \mathrm{H}_{7}\right), 8.09$ (dd, $J=4$. 
$\left.9 \mathrm{~Hz}, J=1.8 \mathrm{~Hz}, 1 \mathrm{H}, \mathrm{H}_{2}\right) \cdot{ }^{13} \mathrm{C} \mathrm{NMR}\left(\mathrm{CDCl}_{3}\right) \delta 32.8$ $\left(\mathrm{NCH}_{3}\right), 115.0\left(\mathrm{C}_{4 \mathrm{a}}\right), 118.2\left(\mathrm{C}_{3}\right), 120.8\left(\mathrm{C}_{6}\right), 131.9\left(\mathrm{C}_{5 \mathrm{a}}\right)$, $134.4\left(\mathrm{C}_{4}\right), 135.2\left(\mathrm{C}_{9}\right), 139.9\left(\mathrm{C}_{9 \mathrm{a}}\right), 143.9\left(\mathrm{C}_{7}\right), 145.8\left(\mathrm{C}_{2}\right)$, $154.3\left(\mathrm{C}_{10 \mathrm{a}}\right)$. EI MS m/z: 215 (M, 100), $200\left(\mathrm{M}-\mathrm{CH}_{3}, 80\right)$. Anal. Calcd for: $\mathrm{C}_{11} \mathrm{H}_{9} \mathrm{~N}_{3} \mathrm{~S}$ C 61.37, H 4.21, N 19.52 . Found: C 61.22; H 4.23; N 19.41.

10-Allyl-1,8-diazaphenothiazine (8) (0.085 g, $70 \%)$; an oil ${ }^{1} \mathrm{H}$ NMR $\left(\mathrm{CDCl}_{3}\right) \delta 4.66\left(\mathrm{~m}, 2 \mathrm{H}, \mathrm{N}-\mathrm{CH}_{2}\right), 5.32(\mathrm{~m}$, $\left.2 \mathrm{H},=\mathrm{CH}_{2}\right), 5.96(\mathrm{~m}, 1 \mathrm{H}, \mathrm{CH}), 6.82(\mathrm{dd}, J=7.5 \mathrm{~Hz}, J=$ $\left.5.1 \mathrm{~Hz}, 1 \mathrm{H}, \mathrm{H}_{3}\right), 7.04\left(\mathrm{~d}, J=5.0 \mathrm{~Hz}, 1 \mathrm{H}, \mathrm{H}_{6}\right), 7.18(\mathrm{dd}$, $\left.J=7.5 \mathrm{~Hz}, J=1.5 \mathrm{~Hz}, 1 \mathrm{H}, \mathrm{H}_{4}\right), 7.89\left(\mathrm{~s}, 1 \mathrm{H}, \mathrm{H}_{9}\right), 8.02$ $\left(\mathrm{m}, 2 \mathrm{H}, \mathrm{H}_{2}, \mathrm{H}_{7}\right) \cdot{ }^{13} \mathrm{C} \mathrm{NMR}\left(\mathrm{CDCl}_{3}\right) \delta 47.6\left(\mathrm{NCH}_{2}\right), 113.0$ $\left(\mathrm{C}_{4 \mathrm{a}}\right), 118.1\left(\mathrm{C}_{3}\right), 119.2\left(\mathrm{C}_{6}\right), 121.1\left(\mathrm{CH}_{2}=\right), 130.2\left(\mathrm{C}_{5 \mathrm{a}}\right)$, $131.2\left(\mathrm{C}_{4}\right), 134.5\left(\mathrm{C}_{9}\right), 137.9(-\mathrm{CH}=), 138.8\left(\mathrm{C}_{9 \mathrm{a}}\right), 140.2$ $\left(\mathrm{C}_{7}\right), 146.4\left(\mathrm{C}_{2}\right), 151.9\left(\mathrm{C}_{10 \mathrm{a}}\right)$. EI MS m/z: $241(\mathrm{M}, 50), 200$ (M- $\mathrm{CH}_{2} \mathrm{CHCH}_{2}, 100$ ). Anal. Calcd for: $\mathrm{C}_{13} \mathrm{H}_{11} \mathrm{~N}_{3} \mathrm{~S} \mathrm{C} 64$. 70, H 4.59, N 17.41. Found: 64.58; H 4.58; N 17.31.

10-Benzyl-1,8-diazaphenothiazine (10) (0.095 g, $65 \%)$; an oil ${ }^{1} \mathrm{H}$ NMR $\left(\mathrm{CDCl}_{3}\right) \delta 5.34\left(\mathrm{~s}, 2 \mathrm{H}, \mathrm{CH}_{2}\right), 6.76(\mathrm{dd}, J=$ $\left.7.2 \mathrm{~Hz}, J=4.8 \mathrm{~Hz}, 1 \mathrm{H}, \mathrm{H}_{3}\right), 6.87\left(\mathrm{~d}, J=5.0 \mathrm{~Hz}, 1 \mathrm{H}, \mathrm{H}_{6}\right)$, $7.22\left(\mathrm{dd}, J=7.2 \mathrm{~Hz}, J=1.4 \mathrm{~Hz}, 1 \mathrm{H}, \mathrm{H}_{4}\right), 7.29(\mathrm{~m}, 5 \mathrm{H}$, $\left.\mathrm{C}_{6} \mathrm{H}_{5}\right), 7.81\left(\mathrm{~s}, 1 \mathrm{H}, \mathrm{H}_{9}\right), 7.96\left(\mathrm{~m}, 2 \mathrm{H}, \mathrm{H}_{2}, \mathrm{H}_{7}\right)$. EI MS $m / z$ : 291 (M, 80), $200\left(\mathrm{M}-\mathrm{CH}_{2} \mathrm{C}_{6} \mathrm{H}_{5}, 100\right)$. Anal. Calcd for: $\mathrm{C}_{17} \mathrm{H}_{13} \mathrm{~N}_{3} \mathrm{~S}$ C 70.08, H 4.50, N 14.42. Found: C 70.00; H 4. 52; N 14.29.

10-(4'-Nitrophenyl)-1,8-diazaphenothiazine (11) (0.120 g, $74 \%) ; m p \quad 171-172{ }^{\circ} \mathrm{C} \quad{ }^{1} \mathrm{H}$ NMR $\left(\mathrm{CDCl}_{3}\right) \delta 6.88(\mathrm{dd}$, $\left.J=7.2 \mathrm{~Hz}, J=5.0 \mathrm{~Hz}, 1 \mathrm{H}, \mathrm{H}_{3}\right), 6.95(\mathrm{~d}, J=5.0 \mathrm{~Hz}, 1 \mathrm{H}$, $\left.\mathrm{H}_{6}\right), 7.21\left(\mathrm{dd}, J=7.2 \mathrm{~Hz}, J=1.6 \mathrm{~Hz}, 1 \mathrm{H}, \mathrm{H}_{4}\right), 7.55(\mathrm{~m}$, $\left.2 \mathrm{H}, 2 \mathrm{H} \mathrm{C}_{6} \mathrm{H}_{4}\right), 7.81\left(\mathrm{dd}, J=5.0 \mathrm{~Hz}, J=1.6 \mathrm{~Hz}, 1 \mathrm{H}, \mathrm{H}_{2}\right)$, $7.96\left(\mathrm{~d}, J=5.0 \mathrm{~Hz}, 1 \mathrm{H}, \mathrm{H}_{7}\right), 8.15\left(\mathrm{~s}, 1 \mathrm{H}, \mathrm{H}_{9}\right), 8.50(\mathrm{~m}$, $\left.2 \mathrm{H}, 2 \mathrm{H} \mathrm{C}_{6} \mathrm{H}_{4}\right)$. EI MS m/z: 322 (M, 100), $276\left(\mathrm{M}^{-N}{ }_{2}, 30\right)$, 200 (M-NO $\left.\mathrm{C}_{6} \mathrm{H}_{4}, 18\right)$. Anal. Calcd for: $\mathrm{C}_{16} \mathrm{H}_{10} \mathrm{~N}_{4} \mathrm{O}_{2} \mathrm{~S} \mathrm{C}$ 59.62, H 3.13, N 17.38. Found: C 59.44; H 3.12; N 17.29.

10-(3'-Nitro-4'-pyridinyl)-1,8-diazaphenothiazine $(0.130 \mathrm{~g}, 80 \%) ; \mathrm{mp} 189-190{ }^{\circ} \mathrm{C}$ lit. (Morak-Młodawska et al., 2012) mp $189-190{ }^{\circ} \mathrm{C}$.

\section{Synthesis of 10-propargyl-1,8-diazaphenothiazines (9)}

To a suspension of $100 \mathrm{mg}(0.5 \mathrm{mmol}) 10 \mathrm{H}$-1,8-diazaphenothiazine (4) in $10 \mathrm{ml}$ DMF was added $80 \mathrm{mg}$ $(0.72 \mathrm{mmol})$ potassium tert-butoxide. The mixture was stirred at room temperature for $1 \mathrm{~h}$. Then to the solution was added dropwise a solution of propargyl bromide $80 \mathrm{mg}$ $(0.64 \mathrm{mmol})$ in toluene. The solution stirred at room temperature for $24 \mathrm{~h}$ and poured onto water $(20 \mathrm{ml})$, extracted with methylene chloride $(20 \mathrm{ml})$, dried with $\mathrm{Na}_{2} \mathrm{SO}_{4}$, and evaporated to the brown oil. The residue was purified by column chromatography (silica gel, $\mathrm{CHCl}_{3}$ ) to yield $85 \mathrm{mg}$ (71\%) of 10-propargyl-1,8-diazaphenothiazine (9), mp 96-97 ${ }^{\circ} \mathrm{C}$.

${ }^{1} \mathrm{H} \quad \mathrm{NMR}: \quad \delta \quad 2.39(\mathrm{t}, \quad J=2.5 \mathrm{~Hz}, \quad 1 \mathrm{H}), 4.61 \quad(\mathrm{t}$, $J=2.5 \mathrm{~Hz}, 2 \mathrm{H}), 6.92(\mathrm{dd}, J=7.5 \mathrm{~Hz}, J=5.1 \mathrm{~Hz} 1 \mathrm{H}$, $\left.\mathrm{H}_{3}\right), 7.23\left(\mathrm{~m}, 2 \mathrm{H}, \mathrm{H}_{4}, \mathrm{H}_{6}\right), 8.10\left(\mathrm{~d}, J=5.5 \mathrm{~Hz}, 1 \mathrm{H}, \mathrm{H}_{7}\right)$, $8.13\left(\mathrm{~s}, 1 \mathrm{H}, \mathrm{H}_{9}\right), 8.15(\mathrm{dd}, J=5.1 \mathrm{~Hz}, J=1.3 \mathrm{~Hz}, 1 \mathrm{H}$, $\mathrm{H}_{2}$ ). EI MS: 239 (M, 100), $200\left(\mathrm{M}-\mathrm{CH}_{2} \mathrm{CCH}, 85\right)$. Anal. Calcd for: $\mathrm{C}_{13} \mathrm{H}_{9} \mathrm{~N}_{3} \mathrm{~S}$ C $65.25, \mathrm{H} 3.79, \mathrm{~N}$ 17.56. Found: C 65.20; H 3.77; N 17.39.

Synthesis of 10-substituted 1,8-diazaphenothiazines 13-19

To a solution of $10 H$-1,8-diazaphenothiazine (4) $(0.100 \mathrm{~g}$, $0.5 \mathrm{mmol})$ in dry dioxane $(10 \mathrm{ml}) \mathrm{NaOH}(0.20 \mathrm{~g}, 5 \mathrm{mmol})$ was added. The mixture was refluxed 1 and $5 \mathrm{~h}$ then the hydrochlorides of dialkylaminoalkyl chloride (3-dimethylaminopropyl, 2-diethylaminoethyl, 3-dimethylamino-2methylpropyl) and hydrochlorides of cycloaminoethyl chloride ( $N$-(2-chloroethyl)-pyrrolidine, 2-(1-methyl-2'piperydinyl)ethylchloride, $\mathrm{N}$-(2-chloroethyl)piperidine, $\mathrm{N}$ (2-chloroethyl)morpholine, $1.5 \mathrm{mmol}$ ) were added. The reaction mixture was refluxed for $24 \mathrm{~h}$. After cooling, dioxane was evaporated in vacuo and residue was dissolved in $\mathrm{CHCl}_{3}(10 \mathrm{ml})$. The extracts were washed with water, dried with anhydrous sodium sulfate, and evaporated in vacuo. The obtained product was purified by column chromatography (aluminum oxide, $\mathrm{CHCl}_{3}$-EtOH 10:1) to give

10-(3'-Dimethylaminopropyl)-1,8-diazaphenothiazine (13) $(0.100 \mathrm{~g}, 70 \%)$; an oil ${ }^{1} \mathrm{H}$ NMR: $\delta 2.00\left(\mathrm{~m}, 2 \mathrm{H}, \mathrm{CH}_{2}\right), 2$. $26\left(\mathrm{~s}, 6 \mathrm{H}, 2 \mathrm{CH}_{3}\right), 2.44$ (t, $J=7.5 \mathrm{~Hz}, 2 \mathrm{H}, \mathrm{NCH}_{2}$ ), 4.10 (t, $\left.J=7.5 \mathrm{~Hz}, 2 \mathrm{H}, \mathrm{NCH}_{2}\right), 6.73\left(\mathrm{~m}, 1 \mathrm{H}, \mathrm{H}_{3}\right), 6.89(\mathrm{~d}, J=4$. $\left.8 \mathrm{~Hz}, 1 \mathrm{H}, \mathrm{H}_{6}\right), 7.16\left(\mathrm{~d}, J=7.2 \mathrm{~Hz}, 1 \mathrm{H}, \mathrm{H}_{4}\right), 7.99(\mathrm{~m}, 2 \mathrm{H}$, $\left.\mathrm{H}_{2}, \mathrm{H}_{7}\right), 8.08\left(\mathrm{~s}, 1 \mathrm{H}, \mathrm{H}_{9}\right) .{ }^{13} \mathrm{C} \mathrm{NMR}\left(\mathrm{CDCl}_{3}\right) \delta 24.2\left(\mathrm{CH}_{2}\right)$,

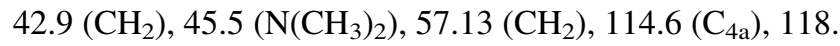
$1\left(\mathrm{C}_{3}\right), 120.8\left(\mathrm{C}_{6}\right), 131.8\left(\mathrm{C}_{5 \mathrm{a}}\right), 134.7\left(\mathrm{C}_{4}\right), 135.5\left(\mathrm{C}_{9}\right), 138$. $7\left(\mathrm{C}_{9 \mathrm{a}}\right), 143.6\left(\mathrm{C}_{7}\right), 145.6\left(\mathrm{C}_{2}\right), 153.6\left(\mathrm{C}_{10 \mathrm{a}}\right) . \mathrm{FAB} \mathrm{MS} m / z$ : $287(\mathrm{M}+1,100), 202\left(\mathrm{M}+1-\mathrm{C}_{3} \mathrm{H}_{6} \mathrm{NC}_{2} \mathrm{H}_{6}, 19\right)$. Anal. Calcd for $\mathrm{C}_{15} \mathrm{H}_{18} \mathrm{~N}_{4} \mathrm{~S}$ C 62.91; H 6.33; N 19.56. Found: C 62.78; H 6.30; N 19.39.

10-(3'-Dimethylamino-2'-methylpropyl)-1,8-diazaphenothiazine (14) $(0.125 \mathrm{~g}, 83 \%)$; an oil ${ }^{1} \mathrm{H}$ NMR: $\delta 1.02(\mathrm{~d}$, $\left.J=6.5 \mathrm{~Hz}, 3 \mathrm{H}, \mathrm{CH}_{3}\right), 2.39\left(\mathrm{~m}, 9 \mathrm{H}, 2 \mathrm{CH}_{3}, \mathrm{CH}_{2}, \mathrm{CH}\right), 4.15$ $\left(\mathrm{m}, 2 \mathrm{H}, \mathrm{CH}_{2}\right), 6.80\left(\mathrm{dd}, J=7.4 \mathrm{~Hz}, J=5.2 \mathrm{~Hz}, 1 \mathrm{H}, \mathrm{H}_{3}\right)$, $6.85\left(\mathrm{~d}, J=5.0 \mathrm{~Hz}, 1 \mathrm{H}, \mathrm{H}_{6}\right), 7.20(\mathrm{dd}, J=7.4 \mathrm{~Hz}, J=1$. $\left.4 \mathrm{~Hz}, 1 \mathrm{H}, \mathrm{H}_{4}\right), 8.02\left(\mathrm{dd}, J=5.2 \mathrm{~Hz}, J=1.4 \mathrm{~Hz}, 1 \mathrm{H}, \mathrm{H}_{2}\right.$ ), $8.09\left(\mathrm{~d}, J=5.0 \mathrm{~Hz}, 1 \mathrm{H}, \mathrm{H}_{7}\right), 8.15\left(\mathrm{~s}, 1 \mathrm{H}, \mathrm{H}_{9}\right) . \mathrm{FAB} \mathrm{MS}$ $m / z: 301(\mathrm{M}+1,100), 202\left(\mathrm{M}+1-\mathrm{C}_{2} \mathrm{H}_{4} \mathrm{NC}_{4} \mathrm{H}_{10}, 18\right)$. Anal. 
Calcd for: $\mathrm{C}_{16} \mathrm{H}_{20} \mathrm{~N}_{4} \mathrm{~S}$ C $63.97 ; \mathrm{H} 6.71 ; \mathrm{N} 18.65$. Found: C 63.80; H 6.73; N 18.42.

10-(2'-Diethylaminoethyl)-1,8-diazaphenothiazine (15) (0. $113 \mathrm{~g}, 75 \%)$; an oil ${ }^{1} \mathrm{H}$ NMR: $\delta 1.04(\mathrm{t}, J=7.3 \mathrm{~Hz}, 6 \mathrm{H}$, $\left.2 \mathrm{CH}_{3}\right), 2.62\left(\mathrm{q}, J=7.3 \mathrm{~Hz}, 4 \mathrm{H}, 2 \mathrm{CH}_{2}\right), 3.62(\mathrm{t}, J=7$. $\left.4 \mathrm{~Hz}, 2 \mathrm{H}, \mathrm{CH}_{2}\right), 4.15\left(\mathrm{t}, J=7.4 \mathrm{~Hz}, 2 \mathrm{H}, \mathrm{CH}_{2}\right), 6.76(\mathrm{dd}$, $\left.J=7.2 \mathrm{~Hz}, J=5.1 \mathrm{~Hz}, 1 \mathrm{H}, \mathrm{H}_{3}\right), 6.83(\mathrm{~d}, J=5.0 \mathrm{~Hz}, 1 \mathrm{H}$, $\left.\mathrm{H}_{6}\right), 7.16\left(\mathrm{dd}, J=7.2 \mathrm{~Hz}, J=1.2 \mathrm{~Hz}, 1 \mathrm{H}, \mathrm{H}_{4}\right), 7.96(\mathrm{dd}$, $\left.J=5.1 \mathrm{~Hz}, J=1.6 \mathrm{~Hz}, 1 \mathrm{H}, \mathrm{H}_{2}\right), 8.03(\mathrm{~d}, J=5.0 \mathrm{~Hz}, 1 \mathrm{H}$, $\left.\mathrm{H}_{7}\right), 8.09\left(\mathrm{~s}, 1 \mathrm{H}, \mathrm{H}_{9}\right)$. FAB MS m/z: $301(\mathrm{M}+1,100), 202$ $\left(\mathrm{M}+1-\mathrm{C}_{2} \mathrm{H}_{4} \mathrm{NC}_{4} \mathrm{H}_{10}, 25\right)$. Anal. Calcd for: $\mathrm{C}_{16} \mathrm{H}_{20} \mathrm{~N}_{4} \mathrm{~S} \mathrm{C}$ 63.97; H 6.71; N 18.65. Found: C 63.81; H 6.73; N 18.41.

10-(2'-Pyrrolidinylethyl)-1,8-diazaphenothiazine (16) (0. $110 \mathrm{~g}, 75 \%)$; an oil ${ }^{1} \mathrm{H} \mathrm{NMR}\left(\mathrm{CDCl}_{3}\right) \delta 1.90(\mathrm{~m}, 4 \mathrm{H}$, $\left.2 \mathrm{CH}_{2}\right), 2.72\left(\mathrm{~m}, 4 \mathrm{H}, 2 \mathrm{CH}_{2}\right), 3.09\left(\mathrm{t}, J=7.2 \mathrm{~Hz}, 2 \mathrm{H}, \mathrm{CH}_{2}\right)$, $4.35\left(\mathrm{t}, J=7.2 \mathrm{~Hz}, 2 \mathrm{H}, \mathrm{NCH}_{2}\right), 6.70(\mathrm{dd}, J=7.6 \mathrm{~Hz}$, $\left.J=5.0 \mathrm{~Hz}, 1 \mathrm{H}, \mathrm{H}_{3}\right), 6.83\left(\mathrm{~d}, J=5.0 \mathrm{~Hz}, 1 \mathrm{H}, \mathrm{H}_{6}\right), 7.17$ $\left(\mathrm{dd}, J=7.2 \mathrm{~Hz}, J=1.5 \mathrm{~Hz} 1 \mathrm{H}, \mathrm{H}_{4}\right), 7.97(\mathrm{dd}, J=5$. $\left.0 \mathrm{~Hz}, J=1.5 \mathrm{~Hz}, 1 \mathrm{H}, \mathrm{H}_{2}\right), 8.04\left(\mathrm{~d}, J=5.0 \mathrm{~Hz}, 1 \mathrm{H}, \mathrm{H}_{7}\right)$, $8.19\left(\mathrm{~s}, 1 \mathrm{H}, \mathrm{H}_{9}\right)$. FAB MS m/z: $299(\mathrm{M}+1,100), 202$ $\left(\mathrm{M}+1-\mathrm{C}_{2} \mathrm{H}_{4} \mathrm{NC}_{4} \mathrm{H}_{8}, 29\right)$. Anal. Calcd for: $\mathrm{C}_{16} \mathrm{H}_{18} \mathrm{~N}_{4} \mathrm{~S} \mathrm{C} 64$. 40; H 6.08; N 18.78. Found: C 64.25; H 6.05; N 18.55.

10-(2'-Piperydinylethyl)-1,8-diazaphenothiazine (17) (0. $110 \mathrm{~g}, 70 \%)$; an oil ${ }^{1} \mathrm{H}$ NMR $\left(\mathrm{CDCl}_{3}\right) \delta 1.47(\mathrm{~m}, 2 \mathrm{H}$, $\left.\mathrm{CH}_{2}\right), 1.63\left(\mathrm{~m}, 4 \mathrm{H}, 2 \mathrm{CH}_{2}\right) 2.54\left(\mathrm{~m}, 4 \mathrm{H}, 2 \mathrm{CH}_{2}\right), 2.75(\mathrm{t}, J=$ $6.8 \mathrm{~Hz}, 2 \mathrm{H}, \mathrm{CH}_{2}$ ), 4.22 (t, $J=6.8 \mathrm{~Hz}, 2 \mathrm{H}, \mathrm{NCH}_{2}$ ), 6.73 $\left(\mathrm{dd}, J=7.6 \mathrm{~Hz}, J=5.0 \mathrm{~Hz}, 1 \mathrm{H}, \mathrm{H}_{3}\right), 6.85(\mathrm{~d}, J=5.0 \mathrm{~Hz}$, $\left.1 \mathrm{H}, \mathrm{H}_{6}\right), 7.14\left(\mathrm{dd}, J=7.6 \mathrm{~Hz}, J=1.6 \mathrm{~Hz} 1 \mathrm{H}, \mathrm{H}_{4}\right), 7.97$ $\left(\mathrm{dd}, J=5.0 \mathrm{~Hz}, J=1.6 \mathrm{~Hz}, 1 \mathrm{H}, \mathrm{H}_{2}\right), 8.03(\mathrm{~d}, J=5.0 \mathrm{~Hz}$, $\left.1 \mathrm{H}, \mathrm{H}_{7}\right), 8.18\left(\mathrm{~s}, 1 \mathrm{H}, \mathrm{H}_{9}\right)$. FAB MS m/z: $313(\mathrm{M}+1,100)$, $202\left(\mathrm{M}+1-\mathrm{C}_{2} \mathrm{H}_{4} \mathrm{NC}_{5} \mathrm{H}_{10}, 20\right)$. Anal. Calcd for: $\mathrm{C}_{17} \mathrm{H}_{20} \mathrm{~N}_{4} \mathrm{~S}$ : C 65.35; H 6.45; N 17.93. Found: C 65.22; H 6.47; N 17.80.

10-(1'-Methyl-2'-piperydinylethyl)-1,8-diazaphenothiazine (18) $(0.116 \mathrm{~g}, 72 \%)$; an oil ${ }^{1} \mathrm{H}$ NMR $\left(\mathrm{CDCl}_{3}\right) \delta 1.30-2$. $15(\mathrm{~m}, 7 \mathrm{H}), 2.36\left(\mathrm{~s}, 3 \mathrm{H}, \mathrm{NCH}_{3}\right), 2.85(\mathrm{~m}, 1 \mathrm{H}, \mathrm{CH}), 4.0(\mathrm{~m}$, $\left.2 \mathrm{H}, \mathrm{NCH}_{2}\right), 6.73\left(\mathrm{dd}, J=7.6 \mathrm{~Hz}, J=5.1 \mathrm{~Hz}, 1 \mathrm{H}, \mathrm{H}_{3}\right), 6$. $87\left(\mathrm{~d}, J=5.0 \mathrm{~Hz}, 1 \mathrm{H}, \mathrm{H}_{6}\right), 7.14(\mathrm{dd}, J=7.6 \mathrm{~Hz}, J=1$. $\left.6 \mathrm{~Hz}, 1 \mathrm{H}, \mathrm{H}_{4}\right), 7.97$ (dd, $J=5.1 \mathrm{~Hz}, J=1.6 \mathrm{~Hz}, 1 \mathrm{H}, \mathrm{H}_{2}$ ), $8.03\left(\mathrm{~d}, J=5.0 \mathrm{~Hz}, 1 \mathrm{H}, \mathrm{H}_{7}\right), 8.06\left(\mathrm{~s}, 1 \mathrm{H}, \mathrm{H}_{9}\right) . \mathrm{FAB} \mathrm{MS}$. $327(\mathrm{M}+\mathrm{H}, 80), 313\left(\mathrm{M}+1-\mathrm{CH}_{3}\right.$ 100). Anal. Calcd for: $\mathrm{C}_{18} \mathrm{H}_{22} \mathrm{~N}_{4} \mathrm{~S}$ C 66.22; H 6.79; N 17.16. Found: C 66.17; H 6. $75 ; \mathrm{N} 17.03$.

10-(2'-Morpholinylethyl)-1,8-diazaphenothiazine (19) (0. $106 \mathrm{~g}, 68 \%)$; an oil ${ }^{1} \mathrm{H} \mathrm{NMR}\left(\mathrm{CDCl}_{3}\right) \delta 1.67(\mathrm{~m}, 4 \mathrm{H}$, $\left.2 \mathrm{CH}_{2}\right), 2.59\left(\mathrm{~m}, 4 \mathrm{H}, 2 \mathrm{CH}_{2}\right), 2.82\left(\mathrm{t}, J=6.6 \mathrm{~Hz}, 2 \mathrm{H}, \mathrm{CH}_{2}\right)$, $4.22\left(\mathrm{t}, J=6.6 \mathrm{~Hz}, 2 \mathrm{H}, \mathrm{NCH}_{2}\right) 6.75(\mathrm{dd}, J=7.2 \mathrm{~Hz}, J=$ $\left.5.1 \mathrm{~Hz}, 1 \mathrm{H}, \mathrm{H}_{3}\right), 6.88\left(\mathrm{~d}, J=5.0 \mathrm{~Hz}, 1 \mathrm{H}, \mathrm{H}_{6}\right), 7.15(\mathrm{dd}$, $\left.J=7.6 \mathrm{~Hz}, J=1.6 \mathrm{~Hz} 1 \mathrm{H}, \mathrm{H}_{4}\right), 7.97(\mathrm{dd}, J=5.1 \mathrm{~Hz}$,
$\left.J=1.6 \mathrm{~Hz}, 1 \mathrm{H}, \mathrm{H}_{2}\right), 8.03\left(\mathrm{~d}, J=5.0 \mathrm{~Hz}, 1 \mathrm{H}, \mathrm{H}_{7}\right), 8.16(\mathrm{~s}$, $\left.1 \mathrm{H}, \mathrm{H}_{9}\right)$. FAB MS m/z: $315(\mathrm{M}+1,40), 202(\mathrm{M}+1-$ $\left.\mathrm{C}_{2} \mathrm{H}_{4} \mathrm{NOC}_{4} \mathrm{H}_{8}, 15\right), 114\left(\mathrm{C}_{2} \mathrm{H}_{4} \mathrm{NC}_{5} \mathrm{H}_{10}, 100\right)$. Anal. Calcd for: $\mathrm{C}_{16} \mathrm{H}_{18} \mathrm{~N}_{4} \mathrm{OS}$ : C 61.12; H 5.77; N 17.82. Found: C 61 . 03; H 5.73; N 17.68.

Synthesis of 10-phthalimidopropyl-1,8diazaphenothiazines (20)

To a stirred solution of $10 \mathrm{H}$-1,8-diazaphenothiazine (4) $(0.100 \mathrm{~g}, 0.5 \mathrm{mmol})$ in dry toluene $(20 \mathrm{ml}) \mathrm{NaH}(0.12 \mathrm{~g}$, $5 \mathrm{mmol}$, washed out with hexane) was added. The mixture was stirred for $20 \mathrm{~min}$ at $\mathrm{rt}$, then refluxed for $1 \mathrm{~h}$ and a solution of $1.5 \mathrm{mmol}, \mathrm{N}$-(3-bromopropyl) phthalimide $0.405 \mathrm{~g}$, in toluene $(10 \mathrm{ml})$ was added. The mixture was refluxed for $24 \mathrm{~h}$. After cooling, the resulted solid was filtered off, toluene was evaporated in vacuo and the residue was purified by column chromatography (aluminum oxide, $\left.\mathrm{CHCl}_{3}\right)$ to give 10-(3'-phthalimidopropyl)-1,8-diazaphenothiazine (20) $(0.110 \mathrm{~g}, 70 \%)$, mp $40-41{ }^{\circ} \mathrm{C}$.

${ }^{1} \mathrm{H}$ NMR $\left(\mathrm{CDCl}_{3}\right) \delta 2.39\left(\mathrm{~m}, 2 \mathrm{H}, \mathrm{CH}_{2}\right), 3.86(\mathrm{t}$, $\left.J=6.1 \mathrm{~Hz}, 2 \mathrm{H}, \mathrm{NCH}_{2}\right), 4.13\left(\mathrm{t}, J=6.0 \mathrm{~Hz}, 2 \mathrm{H}, \mathrm{NCH}_{2}\right)$, $6.77\left(\mathrm{dd}, J=7.1 \mathrm{~Hz}, J=4.9 \mathrm{~Hz} \mathrm{~Hz}, 1 \mathrm{H}, \mathrm{H}_{3}\right), 6.88(\mathrm{~d}$, $\left.J=5.0 \mathrm{~Hz}, 1 \mathrm{H}, \mathrm{H}_{6}\right), 7.14(\mathrm{dd}, J=7.1 \mathrm{~Hz}, J=1.4 \mathrm{~Hz}$, $\left.1 \mathrm{H}, \mathrm{H}_{4}\right), 7.71\left(\mathrm{~m}, 2 \mathrm{H}_{\text {phthalimide }}\right), 7.79(\mathrm{dd}, \mathrm{dd}, J=4.9 \mathrm{~Hz}$, $\left.J=1.4 \mathrm{~Hz}, 1 \mathrm{H}, \mathrm{H}_{2}\right), 7.82\left(\mathrm{~m}, 2 \mathrm{H}_{\text {phthalimide }}\right), 7.98(\mathrm{~s}, 1 \mathrm{H}$, $\left.\mathrm{H}_{9}\right), 8.07\left(\mathrm{~d}, J=5.0 \mathrm{~Hz}, 1 \mathrm{H}, \mathrm{H}_{7}\right)$. FAB MS m/z: 389 $(\mathrm{M}+\mathrm{H}, 100), 201\left(\mathrm{M}+1-\left(\mathrm{CH}_{2}\right)_{3} \mathrm{~N}(\mathrm{CO})_{2} \mathrm{C}_{6} \mathrm{H}_{4}, 30\right)$. Anal. calcd. For $\mathrm{C}_{21} \mathrm{H}_{16} \mathrm{~N}_{4} \mathrm{O}_{2} \mathrm{~S}$ : C 64.93, H 4.15, N 14.42. Found: C 64.82; H 4.14; N 14.29.

\section{Hydrolysis of 10-phthalimidopropyl-1,8-} diazaphenothiazine (20)

To a solution of 10-phthalimidopropyl-1,8-diazaphenothiazine (20) $(0.388 \mathrm{~g}, 1 \mathrm{mmol})$ in $\mathrm{EtOH}(20 \mathrm{ml}) 80 \%$ aqueous solution of hydrazine $(0.2 \mathrm{ml}, 5 \mathrm{mmol})$ was added. The mixture was refluxed for $2 \mathrm{~h}$. After cooling, the reaction mixture was acidified with conc. hydrochloric acid to $\mathrm{pH}$ 2. The solution was concentrated and the resulted solid was filtered off. The filtrate was alkalized with $10 \%$ aqueous solution of sodium hydroxide and extracted with $\mathrm{CHCl}_{3}(3 \times 10 \mathrm{ml})$. The extracts were washed with water, dried with anhydrous sodium sulfate, and evaporated in vacuo. The obtained residue with 10-aminopropyl-1,8-diazaphenothiazine (21) was fast used in the synthesis of the amide derivatives of 1,8-diazaphenothiazines (22-24).

Synthesis of 10-(3'-acetamidopropyl)-1,8diazaphenothiazine (22)

To a suspension with the oil of 10-aminopropyl-1,8-diazaphenothiazine $(\mathbf{2 1})(0.129 \mathrm{~g}, \quad 0.5 \mathrm{mmol})$ in pyridine 
$(5 \mathrm{ml})$ acetic anhydride $(1.48 \mathrm{ml}, 1.5 \mathrm{mmol})$ was added and the mixture was stirred at $\mathrm{rt}$ for $2 \mathrm{~h}$. After evaporation of pyridine in vacuo the residue was dissolved in $\mathrm{CHCl}_{3}$ $(10 \mathrm{ml})$. The solution was washed with water, dried with anhydrous sodium sulfate, and evaporated in vacuo. The residue was purified by column chromatography (aluminum oxide, $\left.\mathrm{CHCl}_{3}\right)$ to give $0.120 \mathrm{~g}(80 \%) 10$ - $\left(3^{\prime}\right.$-acetamidopropyl)-2,7-diazaphenothiazine (22), $\mathrm{mp} 120^{\circ} \mathrm{C}$.

${ }^{1} \mathrm{H}$ NMR $\left(\mathrm{CDCl}_{3}\right) \delta 2.05\left(\mathrm{~s}, 3 \mathrm{H}, \mathrm{CH}_{3}\right), 2.07(\mathrm{~m}, 2 \mathrm{H}$, $\mathrm{CH}_{2}$ ), 3.44 (m, 2H, $\mathrm{NCH}_{2}$ ), 3.96 (t, $J=6.6 \mathrm{~Hz}, 2 \mathrm{H}, \mathrm{NCH}_{2}$ ), $5.99($ broad s, $1 \mathrm{H}, \mathrm{NH}), 6.73(\mathrm{dd}, J=7.2 \mathrm{~Hz}, J=5.0 \mathrm{~Hz}$, $\left.1 \mathrm{H}, \mathrm{H}_{3}\right), 6.85\left(\mathrm{~d}, J=5.0 \mathrm{~Hz}, 1 \mathrm{H}, \mathrm{H}_{6}\right), 7.14(\mathrm{dd}$, $\left.J=7.2 \mathrm{~Hz}, J=1.4 \mathrm{~Hz}, 1 \mathrm{H}, \mathrm{H}_{4}\right), 7.97(\mathrm{dd}, J=5.0 \mathrm{~Hz}$, $\left.J=1.4 \mathrm{~Hz} 1 \mathrm{H}, \mathrm{H}_{2}\right), 8.03\left(\mathrm{~d}, J=5.0 \mathrm{~Hz}, 1 \mathrm{H}, \mathrm{H}_{7}\right), 8.18(\mathrm{~s}$, $\left.1 \mathrm{H}, \mathrm{H}_{9}\right)$. FAB MS m/z: $301(\mathrm{M}+\mathrm{H}, 100), 202(\mathrm{M}+1-$ $\mathrm{C}_{3} \mathrm{H}_{5} \mathrm{NHCOCH}_{3}, 30$ ). Anal. calcd. For $\mathrm{C}_{15} \mathrm{H}_{16} \mathrm{~N}_{4} \mathrm{OS}: \mathrm{C}$ 59.98; H 5.37; N 18.65. Found: C 59.83; H 5.35; N 18.55.

\section{Synthesis of 10-(3'-methanesulfonamidopropyl)-1,8- diazaphenothiazine (23)}

To a stirred solution of oil with 10-aminopropyl-1,8-diazaphenothiazine (21) $(0.129 \mathrm{~g}, 0.5 \mathrm{mmol})$ in a mixture of $\mathrm{CH}_{2} \mathrm{Cl}_{2}(5 \mathrm{ml})$ and $10 \%$ aqueous $\mathrm{Na}_{2} \mathrm{CO}_{3}$ solution $(5 \mathrm{ml})$ a solution of methanesulfonyl chloride $(0.12 \mathrm{ml}$, $1.5 \mathrm{mmol})$ in $\mathrm{CH}_{2} \mathrm{Cl}_{2}(3 \mathrm{ml})$ was added. The solutions were stirred at $\mathrm{rt}$ for $24 \mathrm{~h}$. The organic phase was separated and aqueous phase was extracted with $\mathrm{CH}_{2} \mathrm{Cl}_{2}(2 \times 5 \mathrm{ml})$. The combined extracts were washed with water $(10 \mathrm{ml})$ and dried with anhydrous sodium sulfate and evaporated in vacuo. The residue was purified by column chromatography (aluminum oxide, $\mathrm{CH}_{2} \mathrm{Cl}_{2}$ ) to give $0.125 \mathrm{~g}$ (74\%) 10-(3'-methanesulfonamidopropyl-1,8-diazaphenothiazine (23) as an oil.

${ }^{1} \mathrm{H}$ NMR $\left(\mathrm{CDCl}_{3}\right) \delta 2.08\left(\mathrm{~m}, 2 \mathrm{H}, \mathrm{CH}_{2}\right), 2.94(\mathrm{~s}, 3 \mathrm{H}$, $\left.\mathrm{CH}_{3}\right), 3.42\left(\mathrm{~m}, 2 \mathrm{H}, \mathrm{NCH}_{2}\right), 4.02\left(\mathrm{t}, J=6.9 \mathrm{~Hz}, 2 \mathrm{H}, \mathrm{NCH}_{2}\right)$, 5.57 (broad s, $1 \mathrm{H}, \mathrm{NH}), 6.74(\mathrm{dd}, J=7.2 \mathrm{~Hz}, J=5.0 \mathrm{~Hz}$, $\left.1 \mathrm{H}, \mathrm{H}_{3}\right), 6.84\left(\mathrm{~d}, J=5.0 \mathrm{~Hz}, 1 \mathrm{H}, \mathrm{H}_{6}\right), 7.14(\mathrm{dd}$, $\left.J=7.2 \mathrm{~Hz}, J=1.4 \mathrm{~Hz} 1 \mathrm{H}, \mathrm{H}_{4}\right), 7.97(\mathrm{dd}, J=5.0 \mathrm{~Hz}$, $\left.J=1.4 \mathrm{~Hz} 1 \mathrm{H}, \mathrm{H}_{2}\right), 8.03\left(\mathrm{~d}, J=5.0 \mathrm{~Hz}, 1 \mathrm{H}, \mathrm{H}_{7}\right), 8.18(\mathrm{~s}$, $\left.1 \mathrm{H}, \mathrm{H}_{9}\right)$. FAB MS m/z: $337(\mathrm{M}+1,100), 202(\mathrm{M}+1-$ $\mathrm{C}_{3} \mathrm{H}_{5} \mathrm{NHSO}_{2} \mathrm{CH}_{3}, 30$ ). Anal. calcd. For $\mathrm{C}_{14} \mathrm{H}_{16} \mathrm{~N}_{4} \mathrm{O}_{2} \mathrm{~S}_{2}$ : C 49.98; H 4.79; N 16.65. Found: C 49.88; H 4.74; N 16.39.

\section{Synthesis of 10-(3'-chloroethylureidopropyl)-1,8-} diazaphenothiazine (24)

To a stirred solution of 10-aminopropyl-1,8-diazaphenothiazine (21) $(0.129 \mathrm{~g}, 0.5 \mathrm{mmol})$ in dry EtOH $(10 \mathrm{ml})$ at $0{ }^{\circ} \mathrm{C}$ 2-chloroethyl isocyanate $(0.87 \mathrm{ml}, 1 \mathrm{mmol})$ was added. The mixture was stirred at $0{ }^{\circ} \mathrm{C}$ for $0.5 \mathrm{~h}$ and at $\mathrm{rt}$ for $24 \mathrm{~h}$. After evaporation of $\mathrm{EtOH}$ in vacuo the residue was purified by column chromatography (aluminum oxide,
$\mathrm{CH}_{2} \mathrm{Cl}_{2}$ ) to give $0.120 \mathrm{~g}(63 \%)$ 10-chloroethylureidopropyl-1,8-diazaphenothiazine $(\mathbf{2 4}), \mathrm{mp} 103{ }^{\circ} \mathrm{C}$.

${ }^{1} \mathrm{H} \mathrm{NMR}\left(\mathrm{CDCl}_{3}\right) \delta 1.75\left(\mathrm{~m}, 2 \mathrm{H}, \mathrm{CH}_{2}\right), 2.10(\mathrm{~m}, 2 \mathrm{H}$, $\left.\mathrm{CH}_{2}\right), 3.49\left(\mathrm{~m}, 4 \mathrm{H}, 2 \mathrm{CH}_{2}\right), 4.46\left(\mathrm{~m}, 2 \mathrm{H}, \mathrm{CH}_{2}\right), 6.76(\mathrm{dd}$, $\left.J=7.2 \mathrm{~Hz}, J=5.1 \mathrm{~Hz}, 1 \mathrm{H}, \mathrm{H}_{3}\right), 6.84(\mathrm{~d}, J=5.0 \mathrm{~Hz}, 1 \mathrm{H}$, $\left.\mathrm{H}_{6}\right), 7.14\left(\mathrm{dd}, J=7.2 \mathrm{~Hz}, J=1.4 \mathrm{~Hz} 1 \mathrm{H}, \mathrm{H}_{4}\right), 7.96(\mathrm{dd}$, $\left.J=5.1 \mathrm{~Hz}, J=1.4 \mathrm{~Hz} 1 \mathrm{H}, \mathrm{H}_{2}\right), 8.01(\mathrm{~d}, J=5.0 \mathrm{~Hz}, 1 \mathrm{H}$, $\left.\mathrm{H}_{7}\right), 8.17\left(\mathrm{~s}, 1 \mathrm{H}, \mathrm{H}_{9}\right)$. FAB MS $m / z: 364(\mathrm{M}+1,30), 202$ $\left(\mathrm{M}+\mathrm{H}-\mathrm{C}_{3} \mathrm{H}_{6} \mathrm{NHCONHCH}_{2} \mathrm{CH}_{2} \mathrm{Cl}, 10\right), 185(2 \mathrm{gly}+\mathrm{H}$, 100). Anal. calcd. for $\mathrm{C}_{16} \mathrm{H}_{18} \mathrm{ClN}_{5} \mathrm{OS}$ : C 52.82, H 4.99, N 19.25. Found: C 52.77; H 4.97; N 19.11.

Biological assays

\section{Preparation of the compounds for biological assays}

The compounds were dissolved in DMSO $(10 \mathrm{mg} / \mathrm{ml})$ and subsequently diluted in RPMI-1640 cell culture medium (see below).

\section{Isolation of the peripheral blood mononuclear cells}

Venous blood from a single donor was withdrawn into heparinized syringes and diluted twice with phosphate-buffered saline. PBMC were isolated by centrifugation on Ficoll-uropoline gradient (density $1.077 \mathrm{~g} / \mathrm{ml}$ ) and centrifuged at $800 \times g$ for $20 \mathrm{~min}$ at $4{ }^{\circ} \mathrm{C}$. The interphase cells, consisting of lymphocytes $(20 \%)$ and monocytes $(80 \%)$ were then washed three times with Hanks' medium and re-suspended in a culture medium, referred to below as the culture medium, consisting of RPMI-1640, supplemented with $10 \%$ fetal calf serum, L-glutamine, sodium pyruvate, 2-mercaptoethanol, and antibiotics, at density of $2 \times 10^{6}$ cells $/ \mathrm{ml}$.

\section{PHA-induced proliferation of human blood mononuclear} cells

The isolated PBMC were distributed into 96-well flatbottom plates in $100 \mu \mathrm{L}$ aliquots $\left(2 \times 10^{5}\right.$ cells/well $)$. PHA was added at a concentration of $5 \mu \mathrm{g} / \mathrm{ml}$. The compounds were tested at doses of 1,10 , and $50 \mu \mathrm{g} / \mathrm{ml}$. DMSO at appropriate dilutions served as control. After a four-day incubation in a cell culture incubator, the proliferative response of the cells was determined by the colorimetric MTT method (Hansen et al., 1989). The results are given in percentage inhibition as compared with appropriate DMSO controls.

Cytotoxicity of the compounds against human blood mononuclear cells

PBMC at density of $2 \times 10^{5} /$ well, re-suspended in the culture medium, were cultured for $24 \mathrm{~h}$ in a cell culture 
incubator with the preparations at indicated concentrations. Cell survival was determined by MTT colorimetric method (Hansen et al., 1989). The results are given in percentage inhibition as compared with appropriate DMSO controls.

\section{Lipopolysaccharide-induced TNF-a production in whole blood cell culture}

Venous blood from a single donor was diluted $10 \times$ with RPMI-1640 medium and distributed in $1 \mathrm{ml}$ aliquots in 24-well culture plates. The cultures were stimulated by addition of $1 \mu \mathrm{g} / \mathrm{ml}$ of LPS from E. coli, O111:B4. The compounds were added to the cultures at concentrations of 5 and $25 \mu \mathrm{g} / \mathrm{ml}$. Higher concentrations of the compounds could not be used because of inhibitory effects on TNF- $\alpha$ production by corresponding DMSO (the solvent) dilutions. Appropriate dilutions of DMSO served as controls. After overnight incubation in a cell culture incubator, the supernatants were harvested and frozen at $-20^{\circ} \mathrm{C}$ until cytokine determination by a biological assay (Espevik and Nissen-Meyer, 1986). The results are given in percentage inhibition as compared with appropriate DMSO controls.

\section{Growth inhibition of tumor cell lines}

L-1210 lymphoma and SW-948 colon tumor cell lines derived from the Collection of Cell Lines of The Institute of Immunology and Experimental Therapy, Wrocław, Poland. The lines were re-suspended in the culture medium and distributed into 96-well flat-bottom plates. L-1210 was present at $1.5 \times 10^{4}$ cells/well while SW-948 and at $2.5 \times 10^{4}$ cells/well. The preparations were added to the wells at the concentration range of $0.1-50 \mu \mathrm{g} / \mathrm{ml}$. Cisplatin was used as a reference drug in the same concentrations. After 3-day incubation in a cell culture incubator, the proliferation was determined using MTT colorimetric method. The data are presented as a mean OD value from quadruplicate wells \pm SE.

\section{Statistics}

The results are presented as mean values \pm standard error (SE) or percentage inhibition $=[$ (control value - tested value)/control value] $\times 100$. Brown-Forsyth's test was used to determine the homogeneity of variance between groups. When the variance was homogenous, analysis of variance (One-way ANOVA) was applied, followed by post-hoc comparisons with the Tukey's test to estimate the significance of the difference between groups. Nonparametric data were evaluated with the Kruskal-Wallis' analysis of variance. Significance was determined at $p<0.05$. Statistical analysis was performed using STATISTICA 6.1 for Windows.
Acknowledgments The work was supported by the Medical University of Silesia (Grant KNW-1-006/P/2/0).

Open Access This article is distributed under the terms of the Creative Commons Attribution License which permits any use, distribution, and reproduction in any medium, provided the original author(s) and the source are credited.

\section{References}

\section{Part CXXXVIII in the series of Azinyl Sulfides}

Aaron JJ, Gaye Seye MD, Trajkovska S, Motohashi N (2009) Bioactive Phenothiazines and Benzo[a]phenothiazines: spectroscopic studies and biological and biomedical properties and applications. Topics in Heterocyclic Chemistry, vol 16. Springer-Verlag, Berlin, pp 153-231

Dasgupta A, Dastridara SG, Shirataki Y, Motohashi N (2008) Antibacterial activity of artificial phenothiazines and isoflavones from plants. Topics in Heterocyclic Chemistry, vol 15. SpringerVerlag, Berlin, pp 67-132

Espevik T, Nissen-Meyer J (1986) A highly sensitive cell line WEHI 164 clone 13, for measuring cytotoxic factor/tumor necrosis factor from human monocytes. J Immunol Methods 95:99-103

Guadagni F, Ferroni P, Palmirotta R, Portarena I, Formica V, Roselli M (2007) Review. TNF/VEGF cross-talk in chronic inflammation-related cancer initiation and progression: an early target in anticancer therapeutic strategy. In Vivo 21:147-161

Gupta RR, Kumar M (1988) Synthesis, properties and reactions of phenothiazines. In: Gupta RR (ed) Phenothiazines and 1,4benzothiazines: chemical and biological aspects. Elsevier, Amsterdam, pp 1-161

Hansen MB, Nielsen SE, Berg K (1989) Reexamination and further development of a precise and rapid dye method for measuring cell growth/cell kill. J Immunol Methods 119:203-210

Kopp E, Strell M (1962) Über 2,7-Diazaphenothiazin. Reaktionen in der pyridinreihe. Arch Pharm 295:99-107

Kopp E, Strell M, Janson R (1963) Verfahren zur Herstellung von 2,7-Diazaphenothiazinen. German Patent DE 1(147):235

Maki Y (1957) Sulfur-containing pyridine derivatives. Smiles rearrangement in pyridine derivatives and synthesis of azaphenothiazine derivatives. Yakugaku Zasshi 77:485-490

Morak B, Pluta K (2007) Synthesis of novel dipyrido-1,4-thiazines. Heterocycles 71:1347-1361

Morak B, Pluta K, Suwinska K (2002) Unexpected simple route to novel dipyrido-1,4-thiazines. Heterocycl Commun 8:331-334

Morak-Młodawska B, Pluta K, Matralis AN, Kourounakis AP (2010) Antioxidant activity of newly synthesized 2,7-diazaphenothiazines. Archiv Pharm Chem Life Sci 343:268-273

Morak-Młodawska B, Suwińska K, Pluta K, Jeleń M (2012) 10-(3'Nitro-4'-pyridyl)-1,8-diazaphenothiazine as the double Smiles rearrangement. J Mol Struct 1015:94-98

Motohashi N, Kawase M, Saito S, Sakagami H (2000) Antitumor potential and possible targets of phenothiazine-related compounds. Curr Drug Targets 1:237-245

Motohashi N, Kawase M, Satoh K, Sakagami H (2006) Cytotoxic potential of phenothiazines. Curr Drug Targets 7:1055-1066

Okafor C (1967) Studies in the heterocyclic series. A novel diazaphenothiazine system. J Org Chem 32:2006-2007

Pluta K, Jeleń M, Morak-Młodawska B, Zimecki M, Artym J, Kocięba M (2010) Anticancer activity of newly synthesized azaphenothiazines in NCI's anticancer screening. Pharmacol Rep 62:319-332 
Pluta K, Morak-Młodawska B, Jeleń M (2009) Synthesis and properties of diaza-, triaza- and tetraazaphenothiazines. J Heterocycl Chem 46:355-391

Pluta K, Morak-Młodawska B, Jeleń M (2011) Recent progress in biological activities of synthesized phenothiazines. Eur J Med Chem 46:3179-3189

Rath S (1957) Dimethylaminopropyl-dipyridothiazane. US Patent $2,789,978$

Rodig OR, Collier RE, Schlatzer RK (1966) Pyridine chemistry. Further studies on the Smiles rearrangement of the 3-amino-2,2' dipyridyl sulfide system. The synthesis of some 1,6-diazaphenothiazines. J Med Chem 9:116-120

Sadandam YS, Shetty MM, Bhaskar Rao A (2009) 10H-Phenothiazines: a new class of enzyme inhibitors for inflammatory diseases. Eur J Med Chem 44:197-202

Silberg IA, Cormos G, Oniciu DC (2006) Retrosynthetic approach to the synthesis of phenothiazines. In Advances in heterocyclic chemistry; Katritzky AR (ed.), Elsevier, New York, vol 90, pp 205-237, and Biological evaluation as potential antiproliferative and antifungal agents. Eur J Med Chem 44:1086-1092

Takahashi T, Maki Y (1958a) Smiles rearrangement in pyridine derivatives and synthesis of benzopyrido- and dipyridothiazine derivatives. Yakugaku Zasshi 78:417-421
Takahashi T, Maki Y (1958b) Sulfur-containing pyridine derivatives. Smiles rearrangement of pyridine derivatives and synthesis of benzopyrido- and dipyrido-1,4-thiazine derivatives. Chem Pharm Bull 6:369-373

Tandon VK, Maurya HK, Tripathi A, Shiva Keshava GB, Shukla PK, Srivastava P, Panda D (2009) 2,3-Disubstituted-1,4-naphthoquinones, 12H-benzo[ $b$ ]phenothiazine-6,11-diones and related compounds: synthesis. Eur J Med Chem 44(3):1086-1092

Umbach GE, Singletary SE, Tomasovic B, Spitzer G, Hug V, Drevinko B (1984) Dose-survival curves of cis-platinum, melphalan, and velban in human granulocyte/macrophage progenitor cells. Int J Cell Cloning 2:335-340

Wajant H (2009) The role of TNF in cancer. Results Probl Cell Differ 49:1-15

Yao X, Panichpisal K, Kurtzman N, Nugent K (2007) Cisplatin nephrotoxicity: a review. Am J Med Sci 334:12-115

Zimecki M, Artym J, Kocięba M, Pluta K, Morak-Młodawska B, Jeleń M (2009) Immunosupressive activities of newly synthesized azaphenothiazines in human and mouse models. Cell Mol Biol Lett 14:622-635 